\title{
REFLEXÕES SOBRE A PRÁTICA PEDAGÓGICA EM UMA ESCOLA MUNICIPAL NO RIO DE JANEIRO
}

\author{
Chreiva Magalhães Malick*, Aline Silva Dejosi Nery, Sônia Cristina Soares Dias \\ Vermelho \\ E-mail*: chreiva@hotmail.com \\ *Universidade Federal do Rio de Janeiro \\ DOI: $10.15628 /$ rbept.2020.11258
}

Artigo submetido em: set/2020 e aceito em: nov/2020

\begin{abstract}
RESUMO
Este artigo traz uma reflexão sobre o contexto escolar no ensino fundamental de uma escola em Manguinhos durante a realização de uma pesquisa qualitativa longitudinal fruto de duas dissertações de mestrado. Inicialmente, discutimos sobre uma possível mudança no papel do docente enquanto mediador dos saberes escolares. Em seguida, abordamos a formação do bairro de Manguinhos, nosso campo de estudo, considerando seus principais contextos sociais, refletindo sobre a educação diante da barbárie e a alfabetização científica. Concluímos este estudo ressaltando a importância de uma educação crítica e emancipadora com enfoque na estratégia de emancipação e valorização da cultura local, enfatizando a necessidade de compreender a relação da escola com a política social de bases críticas.
\end{abstract}

Palavras-chave: Educação. Formação Docente. Teoria Crítica. Alfabetização Científica. Manguinhos.

\section{REFLECTIONS ON PEDAGOGICAL PRACTICE AT A FUNDAMENTAL LEVEL SCHOOL IN RIO DE JANEIRO}

\begin{abstract}
This article reflects on the school context in the elementary school of a school in Manguinhos during the realization of a qualitative longitudinal research resulting from two master's dissertations. Initially, we discussed a possible change in the role of the teacher as a mediator of school knowledge. Then, we approach the formation of the neighborhood of Manguinhos, our field of study, considering its main social contexts, reflecting on education in the face of barbarism and scientific literacy. We concluded this study by emphasizing the importance of a critical and emancipatory education with a focus on the strategy of emancipation and valorization of local culture, emphasizing the need to understand the relationship of the school with the social policy of critical bases.
\end{abstract}

Keywords: Education. Teacher Education. Critical Theory. Scientific Literacy. Manguinhos. 


\section{INTRODUÇÃO}

Diversos teóricos se incumbiram da tarefa de pensar e investigar os caminhos em que se desenha o processo de aprendizagem, seja ela cognitiva, afetiva ou psicomotora. Com isso, podemos considerar que no processo ensino-aprendizagem, a tendência é de que o acesso do aluno à informação dependa cada vez menos do professor, pois com a evolução tecnológica, ela chega até nós de variadas formas e com grande velocidade.

Nessa realidade o que se pretende é que

(...) o papel do docente passa a ser ajudar o aluno a selecionar os dados mais relevantes, interpretá-los, relacioná-los e contextualizá-los, para integrar a informação ao seu contexto pessoal - intelectual e emocional - ajudando o aluno a tornar a informação significativa para ele. (REIS, 2009, p. 81).

Dessa forma, a escola passa a ser mais abrangente no sentido de coletar informações externas, advindas da sociedade, e utilizá-las dentro da sala de aula, atrelando o conteúdo das disciplinas a estas situações. Esse movimento de captação de informações descaracteriza o empoderamento da escola como detentora do saber. "Assim, parece que se pode afirmar que a globalização determinou, em tempos que nos são muito próximos, uma inversão no fluxo do conhecimento". (CHASSOT, 2003, p. 90).

Com a globalização, eclodiu uma inversão no fluxo do conhecimento, pois, se o sentido ocorria da escola para a comunidade, hoje ele assume um sentido inverso. Ou seja, quer dizer que é o mundo exterior que invade a escola, e isso se deve em parte, ao avanço tecnológico, mas, até que ponto, esse sentido da escola para a comunidade não deve ser considerado também o inverso, da comunidade para a escola? E aqui, considerando-se os saberes populares?

Reflexões como essa, apontam para uma possível mudança no papel do docente enquanto mediador, pois, o trabalho docente é uma atividade sistemática, que requer a atenção sobre a aprendizagem dos educandos e a consciência do seu papel em sua ação pedagógica. Segundo Libâneo (2013, p. 246), "o planejamento é um processo de racionalização, organização e coordenação da ação docente, articulando a atividade escolar e a problemática do contexto social".

Deve-se entender que a ação docente não se baseia em preenchimento de formulários e dar conceitos às atividades desempenhadas pelos alunos. Ela vai além disso, requer do docente o conhecimento do seu papel transformador na vida dos seus alunos e, com isso, torna-se fundamental ele ter 
conhecimento sobre o significado da concepção curricular no desenvolvimento de seu trabalho e no aprimoramento de sua formação.

Entretanto, a sala de aula e as escolas no Rio de Janeiro apresentam situações que requerem muito mais do que a teoria estudada e planejada nos currículos formulados para serem seguidos ao longo do ano letivo. A escola idealizada e pensada nestes documentos não confere com a escola pública real, onde muitas vezes o docente não consegue seguir um tempo de aula sem haver imprevistos causados por fatores externos à escola, que podem colocar em risco a vida dos alunos, como a violência local. Por isso, sabemos que nem todas as escolas são iguais, os contextos interferem nas instituições, assim como, na condição para a realização de uma prática pedagógica.

Paulo Freire (2005), ressalta a preocupação com a formação docente quando trata dessa necessidade de estar sempre atento a que tipo de educação está sendo oferecida nas escolas. $E$ ressalta a urgência em se ter um cuidado e uma atenção especial com a reflexão, para que os educandos não sejam meros repetidores de rotinas automáticas de conhecimento teórico, sem ética, preocupação social e sem criticidade do mundo a sua volta.

Silva (2006) concorda com Freire ao ressaltar a importância da Alfabetização Científica (AC) para a emancipação dos educandos. Segundo Silva (2006), este é um assunto que tem ganhado destaque no contexto do ramo das ciências. $O$ autor fala a respeito da interação entre meio acadêmico e meio social; e ainda ressalta que este assunto não é algo recente, visto que fenômenos poderiam ser explicados e amplamente divulgados desde o século XVIII sem que esta prática fosse nomeada como AC, e assim, cumprindo 0 papel de mediação entre esses campos que se mostram tão fecundos para a atuação dela, quanto para a sua disseminação, principalmente, nas áreas de formação profissional e docente nas ciências e na tecnologia.

Sob a óptica da AC, ela promove o pensamento crítico, sendo tema de estudo e pesquisa que leva à adoção de medidas que promovam uma educação voltada para desenvolver as habilidades investigativas dos estudantes, pois, se bem preparados criticamente, não se tornarão escravos da ignorância.).

Por isso, diante o exposto, é nessa perspectiva que o presente trabalho foi desenvolvido. Essa reflexão parte de uma pesquisa longitudinal, com base nos estudos no campo da Educação, Ciência e Tecnologia, que se desenvolveu através de uma investigação empírica e participante realizada em uma escola municipal de nível fundamental com discentes, moradores de uma área carente e marginal, cujo objetivo geral foi construir experiências formativas emancipadoras para os docentes e discentes em situação de vulnerabilidade social numa ação educativa como meio de ressignificar a formação docente e a vida escolar, bem como, incitar a autoestima e a autonomia estudantil. 
Neste sentido, cabe uma contextualização do bairro e da escola onde a pesquisa foi realizada ao investigar as condições da escola pública, da prática pedagógica, da formação docente e da formação para a cidadania.

\section{CONTEXTO DE MANGUINHOS}

Localizado na zona norte da cidade do Rio de Janeiro, a formação do bairro de Manguinhos que é composto por diversas favelas, começou com habitações populares alojadas devido a ações individuais e de grupos, mas também por meio das políticas públicas habitacionais com um quadro que contrapõe 0 abandono dos governantes e a luta dos moradores frente a situação da moradia (FERNANDES; COSTA, 2013). Pode-se dizer que a formação das favelas é historicamente caracterizada por lutas populares por moradias entre trabalhadores pobres que se estabeleceram em áreas periféricas dos centros urbanos à procura de trabalho. Assim, hoje em dia, Manguinhos é conhecido como "um espaço de resistência, um espaço social heterogêneo e dinâmico, onde múltiplas demandas e necessidades sociais desafiam a gestão cotidiana das políticas públicas". (CUSTÓDIO, 2016, p. 18).

Esse contexto social já havia sido indicado por Adorno (1995) como uma estratégia para manter a opressão social. Segundo ele, esse é:

Um esquema sempre confirmado na história das perseguições é o de que a violência contra os fracos se dirige principalmente contra os que são considerados socialmente fracos e ao mesmo tempo, seja isto verdade ou não, felizes. (ADORNO, 1995, p. 122).

A caracterização da favela como Comunidade, é afirmada por Freire (2008) e Fernandes e Costa (2013), como uma forma de rompimento com a lógica da exclusão e procura promover a expectativa quanto a promoção da integração da favela à cidade e não a sua exclusão, mostrando que a diferença é atributo relacionado com uma identidade social. São processos sociais promovidos pelos moradores para romper com o preconceito tanto em relação à provisoriedade, quanto à violência e marginalidade que lhe são apregoadas. Por isso, a denominação do lugar não é uma questão de escolha somente, elas representam maneiras distintas de olhar e agir sobre o lugar; por isso a importância em compreender a forma como são operacionalizadas pelos atores, sendo seus sentidos construídos e reconstruídos dinamicamente no cotidiano de suas interações sociais.

Portanto, a utilização da palavra "comunidade" em substituição à 'favela' talvez não convém, pois é mais uma forma de maquiar a imagem que as 
pessoas têm das favelas, já que modificar a palavra "favela" por "comunidade" não altera a percepção, as práticas e nem o andamento do discurso e as representações existentes naquele entorno que se faz presente no cotidiano de Manguinhos. Os traços negativos existentes nas favelas permanecem, mesmo se a pessoa chamar estes espaços de "comunidades". (BIRMAN, 2008; FERNANDES E COSTA, 2013).

\section{A EDUCAÇÃO DIANTE DA BARBÁRIE E A ALFABETIZAÇÃO CIENTÍFICA}

As questões que envolvem a preocupação de porquê ensinar, o que ensinar e como ensinar ciências não são recentes no cenário educacional. Libâneo (1986) ao discutir a questão da democratização da escola pública questiona os métodos de ensino e sobre a importância do objetivo quanto ao privilégio e a aquisição do saber e do saber vinculado às realidades sociais, sendo preciso que os métodos favoreçam a correspondência dos conteúdos com os interesses dos alunos, e que estes possam reconhecer nos conteúdos o auxílio ao seu esforço de compreensão da realidade (prática social).

Mas esse esforço do professor em orientar, em abrir perspectivas a partir dos conteúdos, implica um envolvimento com o estilo de vida dos alunos, tendo consciência inclusive dos contrastes entre sua própria cultura e a do aluno. Não se contentará, entretanto, em satisfazer apenas as necessidades e carências; buscará despertar outras necessidades, acelerar e disciplinar os métodos de estudo, exigir o esforço do aluno, propor conteúdos e modelos compatíveis com suas experiências vividas, para que ele se mobilize para uma participação ativa. É obvio que o adulto por ter mais conhecimento acerca dos fatos sociais, dispõe de uma formação para ensino diante dos conhecimentos, cabendo a ele realizar análise dos conteúdos em confronto com as realidades sociais vividas pelo seu público escolar (LIBÂNEO, 1986).

Do ponto de vista educacional, historicamente, os embates teóricos acerca do papel da escola e da educação têm gerado teorias da educação que são classificadas de duas formas: uma entende que a escola pode ser um instrumento de equalização social, de superação da marginalidade; enquanto a outra teoria compreende a educação como um instrumento de discriminação social, sendo assim, um fator de marginalização (SAVIANI, 2012).

Ao tratar sobre a marginalidade e as relações entre a educação e a sociedade, Saviani entende que não seja "(...) um fenômeno acidental que afeta individualmente um número maior ou menor de seus membros, o que, no entanto, constitui um desvio, uma distorção que não só pode como deve ser corrigida". (SAVIANI, 2012, p. 04). 
Sem dúvida, os julgamentos com base em valores escolares têm um papel, sendo a maneira de se organizar a sociedade comparada com outras maneiras possíveis, maneiras que se consideram oferecer melhores possibilidades de suavizar a luta do homem pela existência, ou seja, uma prática histórica específica comparada com as suas próprias alternativas históricas. Essa é a realidade da luta da formação de Manguinhos que passou e passa por problemas de autoritarismo e descaso do Estado, aspectos que geralmente passam quase despercebidos para quem não vive naquele contexto, ampliando o sentimento de inferioridade e de diferença cultural entre as pessoas que vivem na cidade, que tem possibilidades e melho acesso aos serviços. Em meio ao processo de permanente marginalização, de preconceito e perseguição, a sociedade impõe a ela mesma uma aproximação com a barbárie, tal como já vivida pela humanidade. Para Adorno (1995), a violência que é praticada nas escolas criou as condições para que a violência se tornasse cotidiana, aceita por todos. Para ele,

a exigência que Auschwitz não se repita é a primeira de todas para a educação. De tal modo ela precede quaisquer outras que creio não ser possível nem necessário justificá-la. Não consigo entender como até hoje mereceu tão pouca atenção. Justificá-la [o holocausto] teria algo de monstruoso em vista de toda monstruosidade ocorrida. Mas a pouca consciência existente em relação a essa exigência [que não aconteça mais os extermínios por preconceito] e as questões que ela levanta provam que a monstruosidade não calou fundo nas pessoas, sintoma da persistência da possibilidade de que se repita no que depender do estado de consciência e de inconsciência das pessoas. (ADORNO, 1995, p. 119).

Quando estamos na escola, por força da rotina, acabamos dando pouca atenção a certas atitudes que ocorrem à nossa volta, como um aluno com conflitos internos, mas como também a naturalização e a pouca ação diante das situações de violência no entorno, dos tiroteios ao redor da escola e de tantos outros atos de barbárie (Figura 1). É fundamental nos conscientizar, denunciar, nos contrapor às ações que promovam a barbárie, principalmente, quando possivelmente a responsabilidade é de outrem. Afinal, a escola não deve ser vista em números, mas como um coletivo de pessoas, de crianças inocentes, jovens com metas e sonhos para a vida. 
Figura 1 - Alunos retirados de sala de aula devido ao tiroteio ao lado da escola.

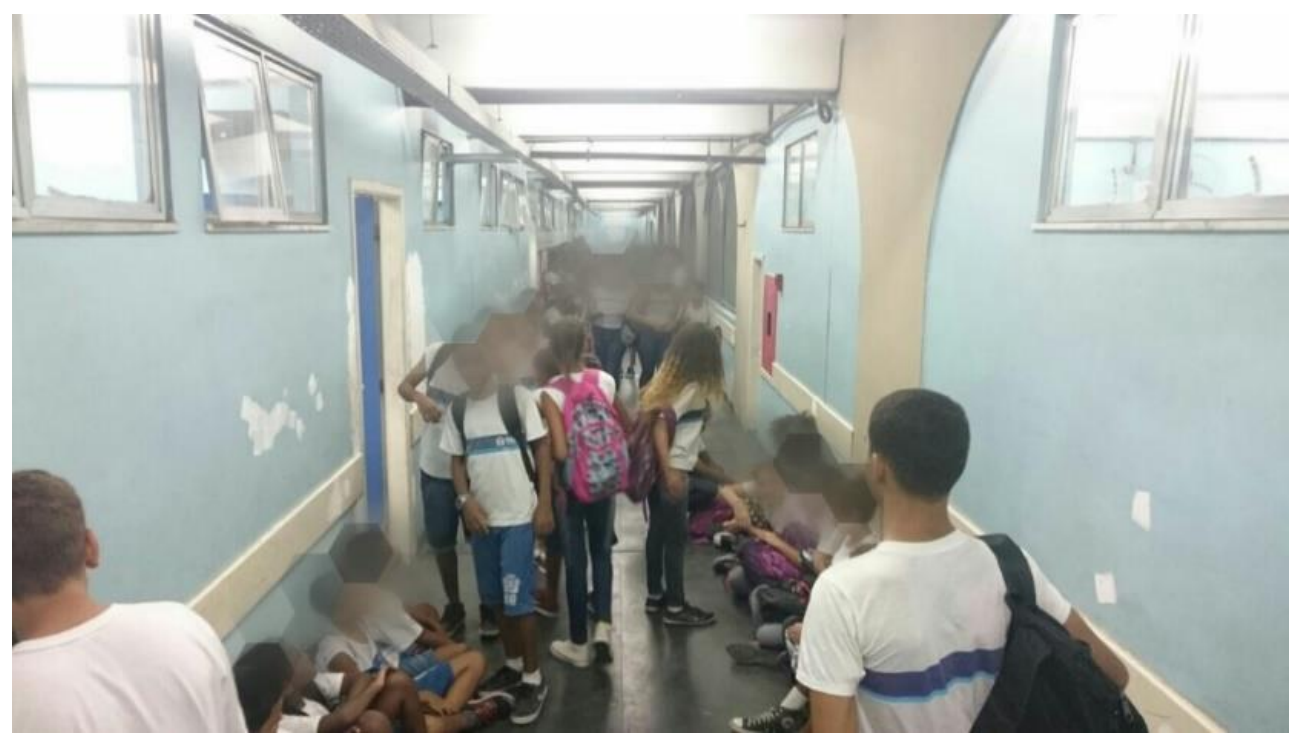

Fonte: acervo pessoal do autor (2017).

A teoria crítica discute as estratégias sociais que conduzem a uma homogeneização dos indivíduos e das suas consciências, o que é adquirido à custa da liberdade de cada um. A regulamentação generalizada da vida, a redução da liberdade, a deturpação das consciências e a atrofia da capacidade crítica são correlatos inevitáveis de uma justiça social e material ampliada (FREITAG, 1994).

Saviani (2012) também reforça essa crítica afirmando que, enquanto houver lutas oriundas de processos históricos de desigualdade social, os esforços educativos devem ser intensificados até quando for superada, e os serviços educativos devem ser mantidos num nível pelo menos suficiente para impedir o reaparecimento de problemas, como o da marginalidade.

A educação traz a possibilidade de se ampliar a margem de autonomia em face da sociedade. Tanto que lhe cabe um papel decisivo na conformação da sociedade evitando sua desagregação e, mais do que isso, garantindo a construção de uma sociedade igualitária (SAVIANI, 2012, p. 4).

A teoria crítica da educação não tem um receituário pedagógico, ela nos ajuda a compreender o funcionamento da escola tal como está constituída, mostrando as condições social e histórica da escola na sociedade capitalista, pondo em evidência aquilo que ela desconhece e mascara, ou seja, seus determinantes sociais e materiais como instrumentos de reprodução das relações de exploração e destruição do indivíduo. Por isso, a necessidade de 
se contrapor à escola na sociedade capitalista que reproduz a dominação e exploração, pois da forma como ela está, acaba por manter seu caráter segregador e marginalizador (SAVIANI, 2012).

$\mathrm{Na}$ escola pesquisada nos deparamos com situações em que a sociedade e sua forma de produtividade imposta "é destruidora do livre desenvolvimento das necessidades e faculdades humanas; sua paz, mantida pela constante ameaça de guerra; seu crescimento, dependente da repressão das possibilidades reais de amenizar a luta pela existência". (MARCUSE, 1973, p. 14).

Lá encontramos não só a barbárie da qual alertava Adorno (1995), com a morte rondando a todos, com as opressões sociais oriundas do racismo, do preconceito, mas também as imposições do Estado sobre a direção da escola que mal tinha tempo para entender mais a fundo o que realmente estava ocorrendo ali. Como educadores, devemos entender a opressão sofrida por todos naquele local e o que leva a tais modos e formas de opressão.

Ao se deparar com as condições atuais que apresentam a necessidade de formar cidadãos e cidadãs que não só saibam ler o mundo onde estão inseridos, "há uma preocupação na busca de ações mais intensas para que formemos profissionais que tenham uma efetiva consciência de cidadania, independência de pensamento e capacidade crítica, que devem adquirir ao longo da escolarização". (CHASSOT, 2011, p. 101).

Diante disso, faz-se necessário considerar o processo de ensinoaprendizagem como um conjunto de conhecimentos pedagógicos que esclarece e justifica as ações didáticas propostas no trabalho docente. Dessa forma, o papel do docente é considerado parte integrante do processo educativo de integralização e de formação do cidadão para o convívio em uma sociedade. Deste modo, Libâneo (2013, p. 15) afirma que é "(...) por meio da ação educativa que o meio social exerce influências sobre os indivíduos e estes, ao assimilarem e recriarem essas influências, tornam-se capazes de estabelecer uma relação ativa e transformadora em relação ao meio social". Nesta concepção, o trabalho docente se compromete com a sociedade ao influenciar na transformação de indivíduos com potencial para serem cidadãos críticos, ativos e participantes em seus diferentes contextos sociais.

No mundo cada vez mais dependente do conhecimento científicotecnológico, a educação científica do século XXI tem se destacado por ações mais consolidadas de popularização da ciência. Por isso, o ensino e a aprendizagem não podem apenas estar limitados à atividade de leitura, escrita e cálculos, mas também desenvolver competências para pensar e lidar com conceitos e problemáticas, e argumentar diante de diversas práticas sociais em que o aluno está inserido. Essas articulações com o contexto criam melhores condições para que o conteúdo aprendido pelo aluno tenha relação com seu cotidiano e com sua vida, dando significado à aprendizagem. 
Nessa perspectiva, a alfabetização científica é tratada por Chassot (2011, p. 62) "como o conjunto de conhecimentos que facilitariam aos homens e mulheres fazer uma leitura do mundo onde vivem", sendo aplicada não no sentido de que a Ciência deva ser ensinada apenas para se formar cientistas, mas para que os alunos e alunas se transformem em homens e mulheres mais críticos e se tornem agentes de transformação do mundo e que o transformem para melhor.

A alfabetização científica tem papel fundamental em transformar o sujeito, tornando-o capaz de selecionar, entender e participar dos movimentos e ações que são realizadas no âmbito científico visando à sociedade como um todo. Essa afirmação é citada por Krasilchik e Marandino (2007, p. 19), em conformidade com o pensamento de Attico Chassot, as quais ressaltam que uma das principais funções do ensino de ciências é a "formação do cidadão científico alfabetizado, capaz de não só identificar o vocabulário da ciência, mas também de compreender conceitos e utilizá-los para enfrentar desafios e refletir sobre seu cotidiano".

Saviani (2012, p. 30) indaga se é possível articular a escola com os interesses dos dominados se "(...) é possível uma teoria da educação que capte criticamente a escola como um instrumento capaz de contribuir para a superação do problema da marginalidade?" A partir desse questionamento, faremos nossas considerações finais sobre o objeto em análise que se segue.

\section{CONSIDERAÇÕES FINAIS SOBRE A EDUCAÇÃO CRÍTICA E EMANCIPADORA NO CONTEXTO ESCOLAR DE MANGUINHOS}

Um dos maiores desafios da educação atualmente é a democratização de acesso aos saberes que favoreça o diálogo entre eles e propicia 0 desenvolvimento de valores ético culturais e socioambientais no intuito de formar cidadãos participativos e que convivam coletivamente e com um ambiente progressivamente mais complexo e com prósperas demandas na produção de bens materiais e simbólicos num mundo globalizado e excludente.

Indo na contramão da opressão, a alfabetização científica mune o cidadão de conhecimento para que ele possa contribuir numa transformação social, sendo capaz de provocar a participação no processo de tomada de decisões. De acordo com Freire (2005), para que os educandos desenvolvam em si a consciência crítica e assim se inserirem no mundo, como transformadores dele, como sujeitos, o autor apresenta como pressupostos a concepção problematizadora e libertadora, contrariando a visão "bancária" da educação, na qual, os homens são vistos como seres da adaptação, do ajustamento e nessa visão, o poder de criação dos educandos é anulado ou minimizado, "o que estimula sua ingenuidade e não sua criticidade, satisfaz aos 
interesses dos opressores: para estes, o fundamental não é o desnudamento do mundo, a sua transformação". (FREIRE, 2005, p. 69).

Muitas das vezes podemos achar que o problema da educação do local é o material humano, que o aluno não é adequado ou os professores não se importam, uma vez que outros alunos, como os de escolas elitistas tem melhor rendimento em relação à avaliação formal (exame), porém devemos ter a sensibilidade de entender a base e o contexto histórico. O que levou aquelas crianças e jovens a serem tão afetados? Os alunos até poderiam ajudar os professores, mas como? Se nem eles sabem por onde começar.

Defendemos que nosso papel como educadores seja despertar a consciência dos alunos sobre os contextos de adversidades que se impõem a elas. Como taxar um aluno, sem considerar as circunstâncias em que a escola se insere, a precariedade dos materiais físicos e pedagógicos, e seus docentes que muitas vezes não vivem naquela área e que sofrem com as ações do Estado, atuando com apostilas impostas, em um local de difícil acesso e possível risco de vida para exercer sua profissão?

Entendemos que a educação é um dos caminhos que leva a uma reflexão crítica, pressuposto para uma formação capaz de se contrapor a violência, condição para não ter atitudes irracionais e violentas. Com isso, entendemos ser fundamental partir da teoria crítica para analisar o contexto escolar para que possamos avaliar melhor a história e os interesses que envolvem a formação dos alunos, percebendo de que forma nossos métodos de ensino podem levar os alunos a um desenvolvimento mais crítico sobre a vida.

Analisar a escola de forma crítica é ver os limites de sua potencialidade como uma forma democrática de mobilidade social, pois isso pode acabar perpetuando as desigualdades de oportunidades dos alunos. As escolas reproduzem as aparências necessárias para a sociedade capitalista: trabalhadores apropriados a cada necessidade dos locais de trabalho, líderes para cargos de chefia e líderes obedientes e subordinados para os cargos de produção. Concordamos com Saviani (2012) de que

do ponto de vista prático, trata-se de retomar vigorosamente a luta contra a seletividade a discriminação e o rebaixamento do ensino das camadas populares. Lutar para garantir um ensino da melhor qualidade possível nas condições históricas atuais. O papel de uma teoria crítica da educação é dar substância concreta a essa bandeira de luta de modo a evitar que ela seja apropriada e articulada com os interesses dominantes (SAVIANI, 2012, p. 31). 
A escola é espaço coletivo para o convívio, trocas, acolhimento e aconchego, onde se garante o bem-estar de crianças, adolescentes, jovens e adultos, no relacionamento entre si e com as demais pessoas, ou seja, a comunidade de modo geral. É nela que se ressignifica e se recria a cultura herdada, reconstruindo as identidades culturais, em que se aprende a valorizar as próprias raízes.

Essa concepção de escola exige desde a construção do currículo até os critérios que orientam a organização do trabalho escolar em sua multidimensionalidade, pois cabe ao entrar em uma escola localizada em um bairro precário que tenhamos o entendimento de que é possível ocorrer uma transformação naquele ambiente marcado pela desigualdade e violência.

Sob essa ótica, cabe dizer que ser professor, docente, pesquisador, educador, mediador, orientador, facilitador, entre outros, é assumir, não só a responsabilidade do ensinar em prol da ciência, arte, cultura, filosofia entre outras vertentes (PESCE; ANDRÉ, 2012). Ao professor cabe explorar o entorno do universo social, político e econômico, existente na relação: homem e mundo. É ultrapassar, os saberes científicos, ampliando-se na existência histórica humana e suas relações psicossociais, simbólicas e filosóficas, préestabelecidas ao entorno do aluno. (RIBEIRO; ALBUQUERQUE, 2014; CUNHA, 2006).

Epistemologicamente, 0 fazer pedagógico ressignifica o pensar, o interrogar, o criticar e o identificar das próprias habilidades, intelectuais e sociais, nas relações docente-discente, professor-aluno, educador-educando e sujeito-objeto. Na construção contínua e efetiva do conhecimento (LIBARDI, 2010). Para a distinção comum entre elementos significativos do saber (CARVALHO, 2007).

Sendo assim, o educando deve ser sujeito da história e não apenas objeto, o que significa que ele não deve se adaptar à realidade, mas mudá-la. Ser alfabetizado cientificamente é compreender que o conhecimento não é algo pronto e acabado, mas está em constante desenvolvimento e que a aquisição de um novo saber não ocorre mediante práticas caracterizadas por meio de transmissão de conteúdos, memorização e regras prontas, as quais só comprometem o raciocínio de homens e mulheres, mas deve acontecer num ambiente propício ao diálogo e que favoreça o exercício de práticas em favor da produção e do desenvolvimento da autonomia de educadores e educando. Na concepção de Freire (1996), o homem e a mulher são seres "programados para aprender" e, portanto, dotados da capacidade de ensinar, conhecer, intervir e mudar.

A educação problematizadora, de acordo com Freire (2005, p. 80), objetiva buscar "a emersão das consciências" a qual resulta na "inserção crítica na realidade" e possui um caráter autenticamente reflexivo que implica no "constante ato de desvelamento da realidade" em oposição à educação bancária que busca manter a imersão" e implica numa "espécie de anestesia, 
inibindo o poder criador dos educandos". O ato de problematizar que engaja os "seres no mundo e com o mundo" tem o poder de desafiar os educandos e quanto mais desafiados, mas obrigados se sentirão de responder ao desafio e, desafiados, conseguem compreender o desafio como um problema num plano de totalidade e em conexões com outros, acarretando uma compreensão cada vez mais crítica e desalienada.

A história e a trajetória da educação em Maguinhos não pode ser eliminada, mas podemos trabalhar em prol para diminuir os danos que são gerados pelas violências sofridas de forma autoritária, de diferenciação entre outras escolas pela cidade e falta de esperança de futuros para aquelas crianças, pois, se depender das condições que aquele ambiente lhes proporciona, terão muita dificuldade para romper com o ciclo de marginalização.

Neste sentido, a pesquisa, ao nos tornar capazes de intervir na realidade mesmo que por pouco tempo, tornou-se tarefa incomparavelmente mais complexa, mas geradora de novos saberes sobre aquele local. Freire (2004) ressalta que ninguém pode estar no mundo, com o mundo e com os outros de forma neutra, pois sempre existem perguntas a serem feitas, que nos fazem ver a impossibilidade de estudar por estudar; de estudar sem se comprometer com os problemas que existem na escola pesquisada.

Diante disso, precisamos compreender o problema do ser, da expressão humana do sujeito que está no processo, que não é fundamentado na resignação da rebeldia, mas sim em face das injustiças que sofrem. Como Freire (2004) diz, mudar é difícil, mas é possível, por isso deve-se programar a ação político-pedagógica. No contexto da escola é preciso ter e renovar saberes, curiosidades, e da prática adquirir conhecimento a partir da sua linguagem e ideologia, com técnicas e métodos de ensino, nunca deixando de lado como eles criam a sua própria sobrevivência, sem impor que o saber acadêmico é o verdadeiro (FREIRE, 2004).

Isso possibilita trazer à tona diálogos do cotidiano e as experiências dos alunos, à geração de debates relacionados ao ensino e a questões ligadas a problemas éticos, religiosos, ideológicos, culturais, étnicos e as relações ao mundo atual.

Portanto, enfatizamos a importância da escola pensar na história e na experiência social de vida do sujeito que enfrenta e incitar valores que condizem com a sua realidade, evidenciando a sua formação. É fundamental que a escola apresente ao aluno a sua capacidade de transformação social. 


\section{REFERÊNCIAS}

ADORNO, T. W. Educação e emancipação. São Paulo: Paz e Terra, 1995. BIRMAN, P. Favela é Comunidade? In: DA SILVA, Luis Antônio Machado (Org). Vida sob cerco: violência e rotina nas favelas do Rio de Janeiro. Rio de Janeiro: Nova Fronteira, 2008.

CARVALHO, V. Sobre conhecimento geral e específico: destaques substantivos e adjetivos para uma epistemologia da enfermagem. In: Escola Anna Nery Revista de Enfermagem, Rio de Janeiro, v. 11, n. 2, p.337-342, 2007.

CHASSOT, A. Alfabetização Científica: uma possibilidade para a inclusão social. In: Revista Brasileira de Educação, Porto Alegre, n. 22, p. 89-100, 2003.

CUSTÓDIO, L. Midiativismo de favela: Reflexões sobre o processo de pesquisa. University of Tampere: School of Communication, Media and Theather. Finland, 2016. Disponível em:

http://www.uta.fi/cmt/index/Midiativismo-de-Favela.pdf. Acesso em: 30 mai. 2020.

FERNANDES, T. M.; COSTA, R. G. As comunidades de Manguinhos na história das favelas no Rio de Janeiro. In: Revista Tempo, Niterói-RJ, v. 19, n. 34, p. 117-133, 2013. Disponível em:

http://www.scielo.br/pdf/tem/v19n34/10.pdf. Acesso em: 24 set. 2020.

FREIRE, L. L. Favela, bairro ou comunidade? Quando uma política urbana torna-se uma política de significados. In: Dilemas: Revista de Estudos de Conflito e Controle Social, v. 1, n. 2, p. 95-114, 2008.

FREIRE, P. Pedagogia da autonomia: saberes necessários à prática educativa. São Paulo: Paz e Terra, 2004.

FREIRE, P. Pedagogia do oprimido. 46ạ . ed. São Paulo: Paz e Terra, 2005. FREITAG, B. A teoria crítica: ontem e hoje. 5. ed. São Paulo: Editora Brasiliense, 1994.

KRASILCHIK, M.; MARANDINO, M. Ensino de ciência e cidadania. 2. ed. São Paulo: Moderna, 2007.

LIBÂNEO, J. C. Democratização da escola pública: a pedagogia críticosocial dos conteúdos. São Paulo: Edições Loyola, 1986.

LIBÂNEO, J. Didática. 2ª edição. São Paulo: Cortez, 2013. 
LIBARDI, D. A. O papel do professor universitário na construção do conhecimento. In: Revista de Educação, São Paulo, v. 13, n. 15, p. 9-26, 2010.

MARCUSE, H. A ideologia da sociedade industrial: 0 homem unidimensional. 4. ed. Rio de Janeiro: Zahar. 1973.

PESCE, M. K.; ANDRÉ, M. E. D. A. Formação do professor pesquisador na perspectiva do professor formador. In: Revista Brasileira de Pesquisa Sobre Formação Docente. Belo Horizonte, v. 4, n. 7, p. 39-50, 2012. Disponível em: < <https://revformacaodocente.com.br/index.php/rbpfp/article/view/62/52>. Acesso em 05 set 2020.

REIS, G. Alinhavo de narrativas: práticas curriculares cotidianas e formação de professoras, $127 \mathrm{f}$. Dissertação de Mestrado - Universidade do Estado do Rio de Janeiro, Programa de Pós-graduação em Educação da Faculdade de Educação, abril, 2009.

RIBEIRO, M. R. M.; ALBUQUERQUE, R. L. A sociedade contemporânea e os desafios da educação superior. Maringá: NEAD-Núcleo de Educação A Distância, 2014.

SAVIANI, D. Escola e democracia. 42. ed. Campinas-SP: Autores Associados, 2012.

SILVA, H. O que é Divulgação Científica? In: Revista Ciência e Ensino, v. 1, n.1, 2006. 